\title{
Uma proposta didática para traduzir as histórias em quadrinhos
}

\section{A didactic proposal for translating comics}

\author{
Elisângela Liberatti ${ }^{*}$
}

Resumo: 0 objetivo deste artigo é apresentar o desenvolvimento de uma proposta de material didático para a formação de tradutores voltada à tradução de histórias em quadrinhos (HQs). Para isso, apresentamos os principais desafios inerentes à tradução de HQs, que compõem a base do conteúdo abordado no material didático proposto. Os desafios impostos ao tradutor de HQs são levantados a partir da literatura (ZANETTIN 2008; CELOTTI 2008; ROSA 2010; LIBERATTI 2012, 2014; entre outros), a partir de entrevistas realizadas com cinco tradutores e dois editores de HQs e também a partir de diretrizes tradutórias apresentadas por uma editora. 0 material didático tem como objetivo auxiliar no desenvolvimento da conscientização de tradutores em formação sobre a linguagem dos quadrinhos, suas especificidades e as principais implicações para a tradução deste hipergênero discursivo.

Palavras-chave: Tradução de quadrinhos; formação de tradutores; tarefas de tradução; teoria funcionalista; desafios tradutórios.

Abstract: The objective of this paper is to present the development of a didactic material proposed for translation training, which focuses on comics translation. To that effect, the main challenges of comics translation are presented, as they form the basis of the didactic material's content. The challenges imposed to the translator of comics are brought up from the literature (ZANETTIN 2008; CELOTTI 2008; ROSA 2010; LIBERATTI 2012, 2014; among others), from interviews made with five comics translators and two comics editors, and from some guidelines presented by a publishing house. The objective of the didactic material is to help develop in trainee

\footnotetext{
* Doutoranda em Estudos da Tradução pela Universidade Federal de Santa Catarina.
} 
LIBERATTI, E. - Proposta didática para traduzir as histórias em quadrinhos

translators the awareness about the language of comics, its specificities and main implications for the translation of such hyper-genre.

Keywords: Comics translation; translator training; translation task; functionalist theory; translation challenges.

\section{Introdução}

Neste artigo, apresento o andamento de minha pesquisa de doutorado, iniciada em 2013, no Programa de Pós-Graduação em Estudos da Tradução, da Universidade Federal de Santa Catarina. O objetivo do estudo é desenhar uma proposta didática para a formação de tradutores que tenha como enfoque a tradução de histórias em quadrinhos (HQs). O material apresentado trabalha com o par-linguístico inglês - português brasileiro, e a proposta didática é elaborada para inserção em fases intermediárias de cursos de bacharelado em Tradução no Brasil, podendo ser adaptada a cada contexto de ensinoaprendizagem. A teoria que informa o material didático é o funcionalismo de Nord (1991), e a metodologia utilizada é o enfoque por tarefas de tradução (HURTAdo AlBIR 1996). Tanto o funcionalismo quanto a abordagem por tarefas de tradução são discutidos mais à frente, na seção "Proposta didática para a formação de tradutores".

Basicamente, a escolha do hipergênero ${ }^{1} \mathrm{HQs}$ para compor o material didático proposto deve-se ao fato de que os quadrinhos são textos repletos de especificidades, sendo que suas particularidades podem influenciar

\footnotetext{
1 Ramos (2011) categoriza as HQs como um hipergênero discursivo que abrange diversos gêneros com elementos quadrinísticos em comum, como, por exemplo, a charge, as graphic novels e as tiras. Neste trabalho, adotamos a classificação de Ramos para os quadrinhos, e os termos "quadrinhos" e "HQs" são utilizados indiscriminadamente para designar o hipergênero discursivo.
} 
LIBERATTI, E. - Proposta didática para traduzir as histórias em quadrinhos

diretamente o processo tradutório, impondo desafios ao tradutor deste tipo de texto. 0 tradutor é um agente fundamental para a difusão de HQs para outros países e culturas, e o aumento da produção e do consumo dos quadrinhos, em conjunto com a globalização, refletem uma necessidade crescente de traduções de HQs.

Até a década de 60, segundo levantamento de Reis (2012), quem traduzia quadrinhos possuía outro(s) ofício(s) que não o de tradutor, como aponta o quadro abaixo:

\begin{tabular}{|l|l|l|}
\hline \multicolumn{3}{|c|}{ Alguns tradutores de quadrinhos ( 1915 a 1960) } \\
\hline & Nome & Profissão central \\
\hline 1 & Alceu Penna & desenhista e estilista \\
\hline 2 & Alfredo Machado & jornalista e redator \\
\hline 3 & Antônio de Paula Dutra & religioso \\
\hline 4 & Henrique Pongetti & jornalista e revisor \\
\hline 5 & $\begin{array}{l}\text { Helena Ferraz de } \\
\text { Abreu }\end{array}$ & Jornalista roterista \\
\hline 6 & Horácio Gutiérrez & desenhista \\
\hline 7 & Nelson Rodrigues & escritor e jornalista \\
\hline 8 & Olavo Bilac & poeta e jornalista \\
\hline 9 & Paulo Luquin Filho & secretário \\
\hline 10 & Wilson Drummond & redator \\
\hline
\end{tabular}

Quadro I - Adaptado de Reis, 2012.

Como podemos observar, o ofício principal dos profissionais apresentados acima não era a tradução - a tradução (de HQs) era apenas um trabalho secundário e eventual para esses profissionais, que o faziam apenas como forma de aumento de renda, somando-a à quantia recebida pelo trabalho prestado às editoras de HQs (REIS 2012). Podemos deduzir, a partir disso, que esses profissionais provavelmente não possuíam formação em tradução. 
LIBERATTI, E. - Proposta didática para traduzir as histórias em quadrinhos

Nos dias de hoje, este cenário não se modificou muito: a partir de entrevistas realizadas com cinco tradutores de quadrinhos, apesar da pequena amostragem, pudemos notar que mais da metade desses profissionais não possuem formação acadêmica em tradução. Ao passo que a não formação dos tradutores de quadrinhos não desvaloriza nem invalida suas traduções, acreditamos que a oferta de meios facilitadores para traduzir quadrinhos tenha validade, pois poderá servir como auxiliadora da eficiência do processo tradutório do tradutor em formação.

Neste contexto, consideramos válida a criação de um material didático que explore a tradução de HQs, suas especificidades e seus desafios. Buscamos, a partir deste material, desenvolver no tradutor-aprendiz uma conscientização a respeito das especificidades impostas pelo hipergênero e como lidar com elas na tradução.

\section{Os quadrinhos, suas especificidades e seus desafios de tradução}

Quando tentamos definir o que são HQs, nos deparamos com uma tarefa nada fácil, justamente porque, como aponta Groensteen (2013), é complicado criarmos uma definição que dê conta de abranger tudo o que é produzido e lançado no mercado todos os anos, como, por exemplo, HQs em potencial, quadrinhos abstratos, quadrinhos experimentais, novos estilos gráficos, etc. Para complicar um pouco mais a situação, temos HQs que podem ser compostas por mais de um estilo, às vezes até dentro de um mesmo quadro (MCCLoud 1995). Hattnher corrobora a afirmação de Groensteen ao dizer que 
LIBERATTI, E. - Proposta didática para traduzir as histórias em quadrinhos

as propostas de definição [de HQs] são marcadas pela impossibilidade de se abarcar todos os possíveis traços constituintes desse suporte. Uma parte das definições que temos [...] não leva em consideração a evolução radical ocorrida nessa arquitetura textual nos últimos trinta anos, pelo menos (HATTNHER 2014: 35, 36).

Para este artigo, trago uma definição que, até o momento, enxergo como a mais aberta e inclusiva do que podemos classificar como HQ: "[c]omo uma arte narrativa visual, as HQs produzem sentido através de imagens que estão em relação sequencial e que coexistem umas com as outras no espaço, com ou sem texto" (MILLER 2007: 96²). Para completar, a definição trazida por Miller cobre tranquilamente as características das tiras utilizadas no material didático que propomos.

Como o cinema, a literatura e outros tipos de arte, as HQs são consideradas uma mídia autônoma, com linguagem autônoma, que possuem especificidades relacionadas ao hipergênero discursivo do qual fazem parte:

[As HQs] seriam vistas como um hipergênero, que apresentaria algumas características comuns a uma gama de gêneros autônomos, a saber: uso de uma linguagem própria, com recursos como balões, legendas, onomatopéias [sic] e outros; predomina o tipo textual narrativo, que tem nos diálogos um de seus elementos constituintes; pode haver personagens fixos ou não; alguns se baseiam em personalidades reais, como os políticos; a narrativa pode ocorrer em um ou mais quadrinhos e varia conforme o formato do gênero, padronizado pela indústria cultural; em muitos casos, o rótulo, o formato e o veículo de publicação constituem elementos que acrescentam informações genéricas ao leitor, de modo a orientar a percepção do gênero em questão; a tendência é de uso de imagens desenhadas, mas ocorrem casos de utilização de fotografias para compor as histórias (RAMOS 2011: 5).

\footnotetext{
${ }^{2}$ As a visual narrative art, [comics] produces meaning out of images which are in a sequential relationship, and which co-exist with each other spatially, with or without text
} 
LIBERATTI, E. - Proposta didática para traduzir as histórias em quadrinhos

Justamente por serem um tipo de texto com linguagem diferenciada, os quadrinhos trazem especificidades que influenciam o processo de tradução desta arte, tais como:

i. Presença de texto não verbal (imagens, cores): como pode ser observado nas diretrizes apresentadas abaixo, o tradutor de quadrinhos geralmente não tem ingerência sobre imagens, salvas raras exceções, quando não há outra saída. Isso se deve aos seguintes fatores: retocar a imagem demanda tempo e dinheiro e pode alterar o equilíbrio estético da página / do quadro. Além disso, fãs normalmente não veem com bons olhos essas modificações estéticas. A presença do texto não verbal nos quadrinhos é uma de suas características mais marcantes, e o fato de a arte na maioria dos casos não ser modificada no texto traduzido pode ser um grande desafio ao tradutor. Essa característica perpassa e influencia a maioria das outras especificidades, trazidas abaixo;

ii. Marcas culturais: podem ser um desafio ainda maior se aparecerem no texto não verbal, sendo que o tradutor deve saber identificá-las, para então decidir o que fazer com elas - caso seja realmente uma barreira na comunicação, pode sugerir retoques na arte ou inserção de nota de rodapé explicativa. Gestos, símbolos, cores e expressões faciais também podem ser específicas à cultura do texto base (TB). Caso apareçam no texto verbal, podem ser desafiadoras devido à falta de espaço para possíveis explicações necessárias que podem aparecer no próprio texto ou em notas de rodapé, sendo estas últimas muitas vezes não muito bem recebidas por leitores de quadrinhos;

iii. Onomatopeias: podem ser específicas à língua/cultura e de difícil correspondência na língua do texto alvo (TA);

iv. Nos quadrinhos, existe uma relação entre o texto verbal e o texto não verbal, sendo necessário que haja, por parte do tradutor, um entendimento das articulações entre imagem e texto. A relação de dependência entre texto verbal e texto não verbal pode ser um desafio ainda maior ao tradutor em casos, por exemplo, de jogos de palavras que só atingem sua função se ligados 
LIBERATTI, E. - Proposta didática para traduzir as histórias em quadrinhos

às imagens, como na tira abaixo, onde temos a polissemia da palavra em inglês "play" - neste contexto, jogar (baseball) ou tocar (piano) ${ }^{3}$ :
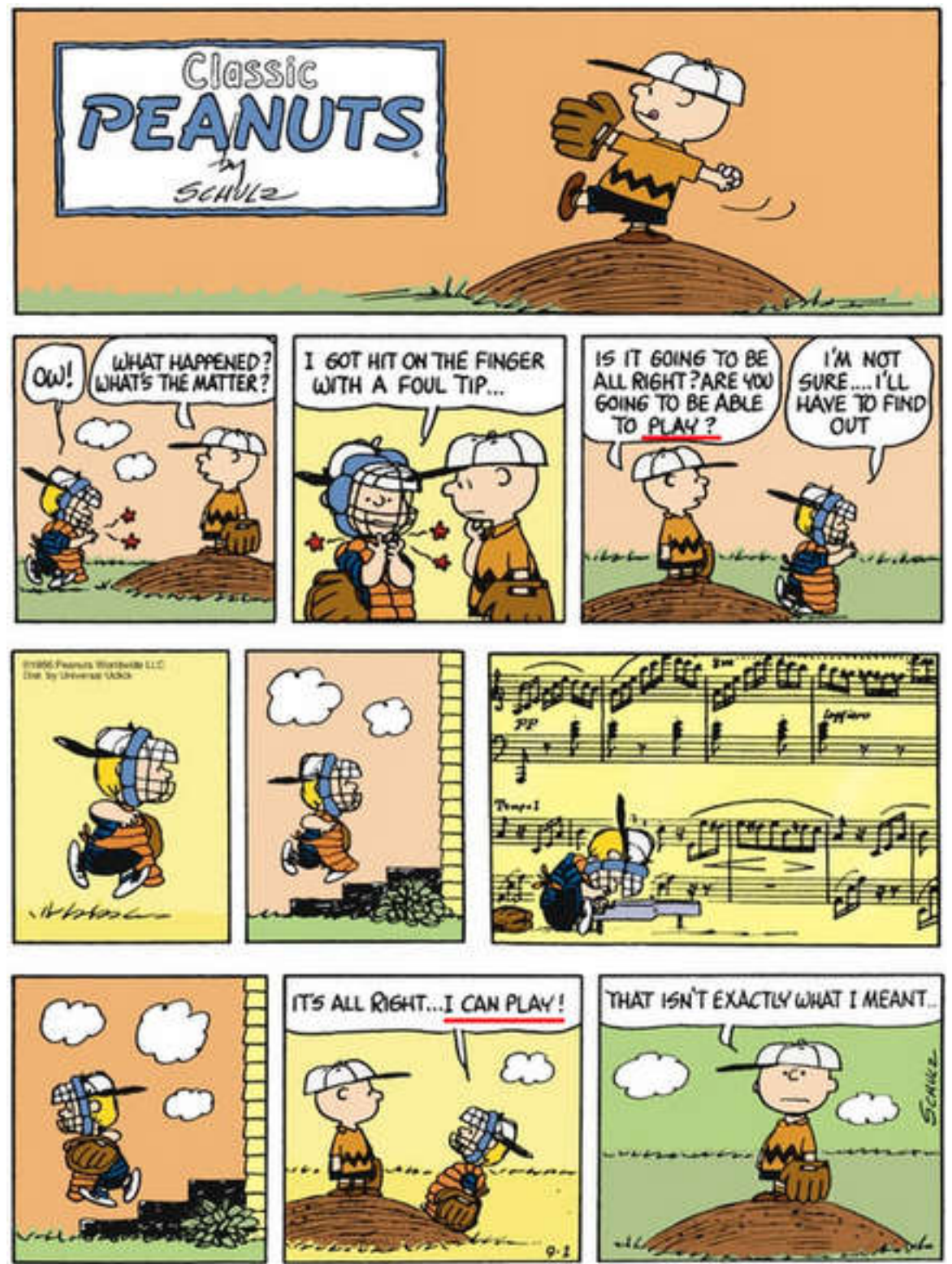

Tira I. Disponível em: http://polyphonyrocks.tumblr.com/post/60008290346

\footnotetext{
${ }^{3}$ Para quem não conhece o personagem Schroeder: ele é apaixonado por música clássica e ama tocar seu piano, sendo um menino prodígio. Assim, na tira em questão, o "play" de seu colega, Charlie Brown, refere-se a jogar baseball, mas Schroeder, justamente por sempre pensar em sua paixão, associa a pergunta de Charlie Brown à possiblidade de tocar piano.
} 
LIBERATTI, E. - Proposta didática para traduzir as histórias em quadrinhos

v. Espaço disponível para o texto verbal: aqui, novamente, temos uma especificidade ligada ao texto não verbal e ao equilíbrio estético da página / do quadro. Conforme apresentando nas diretrizes abaixo, o tradutor deve buscar manter em sua tradução mais ou menos a mesma extensão do TB, para que o tamanho do balão não necessite de retoques. Os retoques são necessários caso a tradução esteja muito mais longa do que o texto original implicando falta de espaço e/ou utilização de letras muito pequenas - ou muito mais curta, implicando muitos espaços "vazios" dentro do balão. Em todos os casos, isso pode desequilibrar a arte da página. Assim, conforme aponta um de nossos entrevistados, faz-se necessário aprender a ser direto e sintético, pois os balões e as caixas de texto têm espaço limitado, diferentemente do que ocorre com o texto em prosa;

vi. Formato dos balões: pode ser bastante específico à cultura e trazer significados diversos, como é o caso de quando comparamos quadrinhos ocidentais e orientais. Mais uma vez, o tradutor deve saber "ler" o significado trazido pelo formato do balão, sugerindo alterações quando julgar necessário ao entendimento da mensagem e à função do texto:
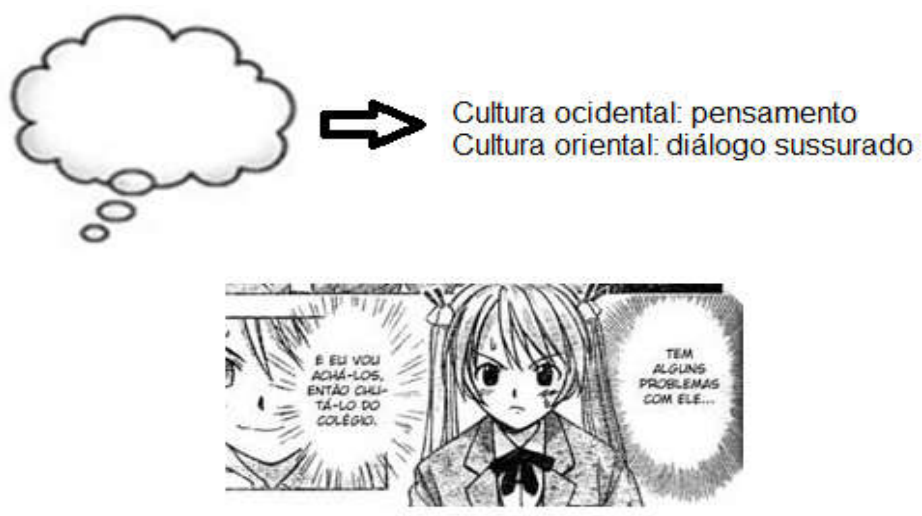

凸

Cultura oriental: pensamento

Figura I - Esquema demonstrando funções diversas de balões ocidentais e orientais, autoria própria (2014). 
LIBERATTI, E. - Proposta didática para traduzir as histórias em quadrinhos

vii. Marcas de oralidade: nos quadrinhos, temos texto escrito, porém este texto representa a fala dos personagens, especialmente nos diálogos (que geralmente ocorrem dentro dos balões). Um dos desafios desta categoria é encontrar um equilíbrio entre a reprodução de um texto escrito que represente a fala do personagem. Um de nossos entrevistados apontou que o tradutor de HQs precisa de sensibilidade aguçada para a tradução de diálogos (um bom "ouvido", por assim dizer), pois são as falas que constituem a base dos quadrinhos em termos de texto. Assim, o tradutor deve saber as idiossincrasias de fala de cada um dos personagens dos textos que traduz, para manter uma coerência dos personagens, além de saber como colocar em texto marcas de oralidade, tais como "hum”, “arrãm”, “certo”, etc. Utilizar abreviações, como "tá", também faz parte de marcas de oralidade, mas, novamente, dependerá dos padrões de fala do personagem. Porém, é papel do tradutor de quadrinhos saber o registro (se mais formal ou mais informal) utilizado pelo personagem. Podemos marcar como uma característica desta categoria os idioletos, socioletos e (pseudo)dialetos utilizados por personagens de algumas HQs - que dialeto utilizar como "correspondente" na língua do TA?;

viii. Gírias e expressões idiomáticas: principalmente se houver alguma relação com a imagem no TB e a gíria/expressão mais adequada para o TA não for condizente com a imagem apresentada no TB (no exemplo abaixo, o TB apresenta humor por meio do sentido literal e do sentido metafórico da expressão “acertou na mosca”):

TradTerm, São Paulo, v. 27, Setembro/2016, pp. 181-200

www.usp.br/tradterm

http://www.revistas.usp.br/tradterm/index 
LIBERATTI, E. - Proposta didática para traduzir as histórias em quadrinhos

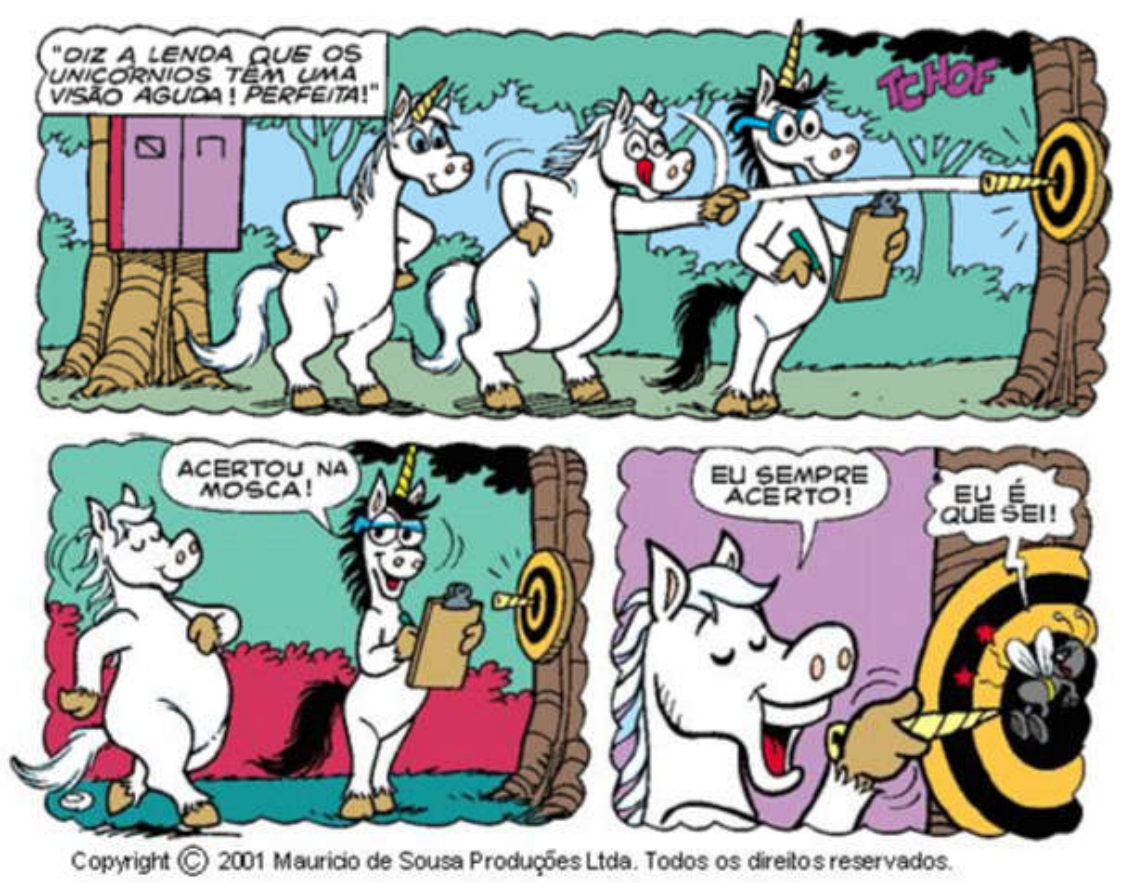

Tira II - Retirada de Rosa, 2010.

Abaixo, trazemos algumas diretrizes para tradução de quadrinhos de uma editora internacional, que exporta suas HQs brasileiras a diversos outros países e culturas (ou seja, suas traduções são do português brasileiro a outras línguas, como o inglês, o espanhol e o italiano). Essas diretrizes são passadas aos tradutores antes de iniciarem seus serviços de tradução:

\section{DIRETRIZES PARA TRADUTORES}

\section{REFERÊNCIAS IMPORTANTES PARA O TRADUTOR E O EDITOR DE HQS:}

$\rightarrow$ As instruções são em português porque o tradutor deverá conhecer 0 português para poder fazer as traduções diretamente do idioma original.

$\rightarrow$ Juntamente com o texto, enviamos a lista de nomes dos personagens em português e no idioma a ser traduzido, para servir como base da tradução. No catálogo constam nomes e uma breve descrição de cada personagem e suas famílias de referência. 
LIBERATTI, E. - Proposta didática para traduzir as histórias em quadrinhos

$\rightarrow 0$ tradutor deve adaptar o texto em português para o (idioma a ser traduzido) coloquial.

$\rightarrow$ As frases devem ser simples para que as crianças entendam sem problemas.

$\rightarrow$ A arte não pode ser modificada.

$\rightarrow$ O número de palavras em cada frase deve ser adequado para caber no espaço de tempo de cada fala em desenhos animados ou do balão das histórias em quadrinhos.

$\rightarrow$ Evitar palavras duras. Exemplo: em vez de dizer que o personagem odeia algo, dizer que ele não gosta de algo.

$\rightarrow$ Se tiverem dificuldade com gírias atuais ou dialetos, estaremos à disposição para esclarecimentos.

$\rightarrow$ Personalidades brasileiras desconhecidas no país do texto traduzido que porventura aparecerem nas histórias deverão ser trocadas por personalidades internacionalmente conhecidas, sempre tendo o cuidado de mudar algumas letras, para não serem iguais aos nomes das celebridades. Exemplo: se no quadrinho tiver uma cantora brasileira loira e for escolhido o nome Britney Spears para a tradução, esse nome deve ser com grafia diferente: Britna Spir ou algo parecido, adequado ao idioma da tradução.

$\rightarrow$ Se os personagens nas histórias estiverem cantando alguma música conhecida somente no Brasil, trocar por música popular do país do idioma traduzido.

$\rightarrow$ Para os títulos das histórias, deve-se ter o cuidado de colocar sempre o nome do personagem principal antes do título.

TRADUÇÃO:

- traduzir todas as onomatopeias;

- traduzir todos os textos do desenho (placas, etc.) tendo o cuidado de informar que aquela palavra ou frase se encontra em uma placa ou em outro local do desenho;

- usar sempre os nomes dos personagens conforme a lista enviada;

- usar sempre o nome do personagem nas falas - até que eles sejam melhor identificados pelo telespectador ou leitor da tradução; 
LIBERATTI, E. - Proposta didática para traduzir as histórias em quadrinhos

- se aparecer um personagem esporádico cujo nome não conste na lista, favor nos informar o nome que será usado e em que script se encontra;

- para traduzir os nomes dos personagens que ainda não estão na lista, por favor sugira um nome de acordo com a personalidade de cada personagem;

- os nomes sugeridos devem ter também mais ou menos o mesmo número de letras do nome original para caber em títulos, embalagens e balões;

- submetam os nomes para nossa prévia aprovação;

- $\quad$ informem o título e a página onde aparece o novo personagem;

- o personagem que utiliza dialeto caipira em sua fala em português deverá ter sua fala traduzida com dialeto caipira da língua do texto traduzido, se houver;

- quando o tradutor não entender a frase, gíria, expressão ou palavra, tirar dúvidas com nosso escritório.

Quadro II - diretrizes para tradutores de editora internacional

É importante ressaltar que as diretrizes de tradução trazidas acima não são necessariamente universais, isto é, dependem de cada linha editorial. Apesar disso, nos mostram, em linhas gerais, o que é exigido do tradutor de quadrinhos no mercado de tradução, o que nos auxilia nas informações sobre o conteúdo a ser abordado no material. Dessa forma, as especificidades apontadas acima podem ser um desafio ao tradutor de HQs, e são as principais delas que utilizamos como base para as tarefas do material didático proposto na tese.

\section{Proposta didática para a formação de tradutores de quadrinhos: algumas considerações e uma pequena amostra}


LIBERATTI, E. - Proposta didática para traduzir as histórias em quadrinhos

Nosso material didático tem como embasamento teórico a didática da tradução funcionalista e como embasamento metodológico a abordagem por tarefas de tradução. Assim, passamos a explicá-las sucintamente, a seguir.

A didática da tradução no viés funcionalista é pautada na teoria funcionalista (NORD 1991), que tem suas raízes em Reiss (1971), com o conceito de tipologia textual, e em Vermeer (1978), com a teoria do escopo 4 . Basicamente, a didática da tradução funcionalista pauta-se na análise textual voltada à tradução, com análise de fatores extratextuais e intratextuais a serem considerados na análise tanto do TB quanto do TA que se pretende produzir. Os fatores extratextuais são fatores pragmáticos, externos ao texto, e podem ser levantados anteriormente à leitura do texto: emissor, intenção do emissor, recepção, meio, lugar, tempo, propósito e função de enunciado. Já os fatores intratextuais são internos ao texto, devendo ser levantados durante ou após a leitura do texto: assunto, conteúdo, pressuposições, estruturação, elementos não verbais, léxico, sintaxe, elementos suprassegmentais (LIBERATTI 2012).

Outro fator tão importante quanto a análise textual para a didática da tradução com viés funcionalista é a apresentação do encargo tradutório. 0 encargo são as instruções de tradução passadas pelo cliente (em sala de aula, podem ser passadas - simuladas - pelo professor). Devem conter informações explícitas ou implícitas sobre o público destinatário, o tempo, o lugar, o motivo, o meio e a função comunicativa que se espera alcançar com o TA (VERMEer 1978, apud ACCÁCIO 2010). Encargos de tradução mais completos e explícitos são dados em fases mais iniciais do curso de formação de tradutores, e encargos progressivamente menos completos e com informações menos explícitas são passados a fases mais avançadas do curso, trabalhandose, assim, a progressão didática do ensino.

\footnotetext{
${ }^{4}$ Não é nosso propósito, neste artigo, nos estendermos nos conceitos sobre a teoria funcionalista de Nord, a Tipologia Textual de Reiss e a Teoria do Escopo de Vermeer. Para mais informações sobre esses conceitos, consulte Nord (1991).
}

TradTerm, São Paulo, v. 27, Setembro/2016, pp. 181-200

www.usp.br/tradterm

http://www.revistas.usp.br/tradterm/index 
LIBERATTI, E. - Proposta didática para traduzir as histórias em quadrinhos

A tarefa de tradução, abordagem metodológica utilizada em nossa proposta didática, é uma cadeia de atividades que visam um mesmo objetivo global e a realização de um produto final - seja ele uma tradução ou não (GonZÁlez DAVIES 2004). Com a abordagem por tarefas de tradução, temos atividades coerentes e que se relacionam entre si.

Devido às características integradoras do enfoque por tarefas de tradução, que reúnem os elementos básicos do desenho curricular (objetivos, conteúdo, metodologia e avaliação), Hurtado Albir (2005) defende que a abordagem por tarefas é uma abordagem bastante eficiente para o ensinoaprendizagem de tradução, como afirma abaixo:

[O enfoque por tarefas] é uma abordagem circular em que todos os componentes [do desenho curricular] aparecem interligados: os objetivos, que [...] podem ser de diferentes tipos; os dados das informações de entrada (input), que formam o ponto de partida da tarefa (um artigo, uma carta, a audição de uma música, etc.), que o aluno processa e que servem para o aprendiz adquirir elementos úteis para a tarefa (podem ser linguísticos ou não linguísticos, autênticos, preparados...); as atividades que compõem a tarefa e que o aluno terá que realizar; o papel do professor e do estudante, que são redefinidos (o estudante passa a ter um papel ativo, com responsabilidade e com capacidade de tomar decisões, e o professor se torna um guia [...]); e, finalmente, a dinâmica com que a tarefa é efetuada: em grupos, em pares, com uma determinada disposição da sala, fora ou dentro da sala de aula, em uma aula convencional ou não, etc. (HURTADO ALBIR 2007: 485 , tradução minha).

5 [El enfoque por tareas] se trata de un planteamiento circular en el que todos los componentes [del diseño curricular] aparecen imbricados: los objetivos, que [...] pueden ser de distinto tipo; los datos de la información de entrada (input), que forman el punto de partida de la tarea (un artículo, una carta, la audición de una canción, etc.) y que el alumno procesa y le sirven para adquirir elementos útiles para la tarea (pueden ser lingüísticos o no lingüísticos, auténticos, preparados...); las actividades que configuran la tarea y que el estudiante tendrá que efectuar; el papel del profesor y del estudiante, que quedan redefinidos (el estudiante pasa a tener un papel activo, con responsabilidad y con capacidad de tomar decisiones, y el profesor pasa a ser un guía [...]); y, por último, la dinámica con que efectúa la tarea: en grupo, por parejas, con una determinada disposición del aula, fuera o dentro de la misma, en un aula convencional o no, etc.

TradTerm, São Paulo, v. 27, Setembro/2016, pp. 181-200

www.usp.br/tradterm

http://www.revistas.usp.br/tradterm/index 
LIBERATTI, E. - Proposta didática para traduzir as histórias em quadrinhos

Ademais, pelo fato de as tarefas de tradução incidirem no processo de aquisição e na melhora da competência tradutória (tendo como consequência um produto final mais bem elaborado), elegemos esta abordagem como nossa base metodológica para o desenho de nosso material. Assim, o desenho do curso aparece com uma sequência de tarefas, de forma que possam ser planejadas, articuladas e avaliadas, e essas tarefas são estruturadas em Unidades Didáticas (UDs), cada qual com seu tema e seu objetivo específico.

Apresentamos abaixo uma amostragem, ainda em fase de formulação, de uma de nossas unidades didáticas e de uma das tarefas de tradução dessa UD. O quadro III mostra a estruturação da UD número dois, e o quadro IV apresenta a estruturação da tarefa de tradução número dois:

Unidade 2: Conhecendo os aspectos convencionais da linguagem dos quadrinhos e suas implicações para a tradução

Objetivo: Possibilitar que os alunos conheçam os aspectos convencionais da linguagem dos quadrinhos e suas implicações para a tradução

Estruturação da unidade

Tarefa 1: Reconhecimento da linguagem específica dos quadrinhos

Tarefa 2: Reconhecimento de desafios tradutórios das HQs apresentadas

Tarefa final: Levantamento de tiras em inglês e/ou em português que tragam desafios tradutórios

Quadro III - Estruturação de uma UD com base na abordagem por tarefas de tradução (HURTADO ALBIR 2005) 
LIBERATTI, E. - Proposta didática para traduzir as histórias em quadrinhos

\section{Estruturação da tarefa 2}

Objetivo: reconhecer os desafios tradutórios das tiras apresentadas

Materiais: tiras do Peanuts, de autoria de Charles Schulz; textos Histórias e traduções em quadrinhos, de Adriano Clayton da Silva e Comics in Translation, de Klaus Kaindl, entregues pela professora (materiais de apoio).

Desenvolvimento da tarefa:

$\rightarrow$ Após ter feito o reconhecimento de aspectos referentes à linguagem das HQs, leia as tiras abaixo ${ }^{6}$ e, em dupla, aponte os desafios impostos ao tradutor em cada uma das tiras, justificando suas respostas com base na leitura dos textos citados acima. Discuta os resultados com o restante da turma e com a professora.
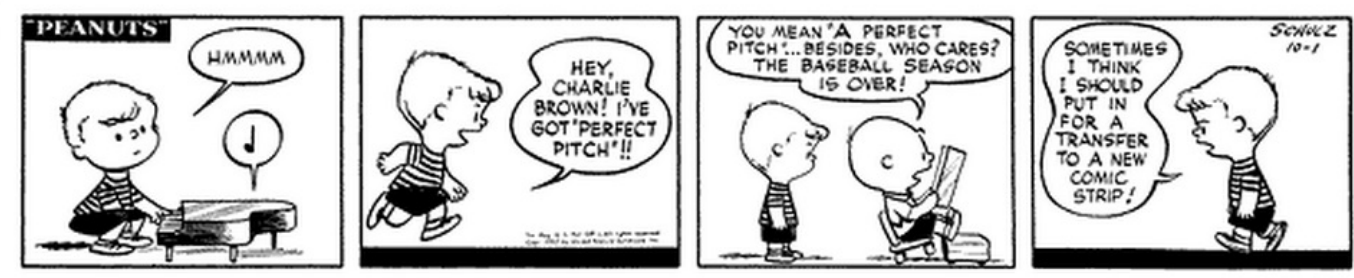

Disponível em: http://peanuts.wikia.com/wiki/October_1952_comic_strips

Avaliação: discussões em sala de aula; apresentação de portfólio com o desenvolvimento da tarefa: levantamento dos desafios impostos pela tradução das tiras apresentadas e justificativas referentes às respostas dadas.

Comentários: --

Quadro IV - Estruturação da tarefa número dois com base na abordagem por tarefas de tradução (HURTADO ALBIR 2005)

\footnotetext{
${ }^{6}$ Neste tópico, trazemos várias tirinhas, cada uma com algumas especificidades, para que os alunos aprendam a reconhecer os desafios tradutórios nelas presentes. Para este artigo, nos detemos a apresentar apenas uma das tiras que pretendemos utilizar.
}

TradTerm, São Paulo, v. 27, Setembro/2016, pp. 181-200

www.usp.br/tradterm

http://www.revistas.usp.br/tradterm/index 
LIBERATTI, E. - Proposta didática para traduzir as histórias em quadrinhos

É importante frisar que a amostragem trazida acima encontra-se ainda em processo de formulação e estruturação, ou seja, não se encontra finalizada e pode ser modificada conforme andamento da pesquisa. Esta é apenas uma pequena amostra de como nosso material didático será desenhado, sempre levando em consideração as bases teóricas e metodológicas que elegemos para a formulação da proposta.

\section{Considerações finais}

Com este trabalho, buscamos contribuir para a desmarginalização do estudo dos quadrinhos, evento que vem ocorrendo paulatinamente, seja na área dos quadrinhos em si, seja na área dos Estudos da Tradução (ainda que em menor grau nesta última). Dessa maneira, esperamos contribuir com a discussão de aspectos que demonstram que este é um tipo de texto riquíssimo em especificidades e que, por isso, merece atenção acadêmica - em nosso caso, quando falamos da tradução desta arte.

Ademais, esperamos que esta proposta didática possa ajudar a estabelecer e consolidar a pesquisa em didática de tradução especializada, no caso, com abordagem voltada especificamente para o ensino de tradução de HQs. A finalidade do ensino da tradução é fazer com que os alunos adquiram as habilidades e os conhecimentos necessários para saber traduzir, isto é, que desenvolvam sua competência tradutória (GALÁN MAÑAS 2007). No caso do material que propomos, esperamos que o aluno desenvolva a competência que julgamos necessária para traduzir HQs.

Como pode ser observado a partir do acima exposto, ainda estamos em processo de estruturação do plano de ensino e das UDs e tarefas que irão fazer parte do nosso material. o que podemos afirmar, por ora, é que as especificidades apresentadas no artigo são a base de nossa proposta, que terá como fundamentos para a formação de tradutores a análise textual voltada à 
LIBERATTI, E. - Proposta didática para traduzir as histórias em quadrinhos

tradução, o encargo de tradução e uma estruturação organizada em tarefas de tradução, com enfoque na exploração do hipergênero quadrinhos.

Nossa proposta pode ser replicada, adaptada e reutilizada em diferentes contextos e para diferentes dinâmicas de sala de aula, conforme interesse e necessidade dos professores e dos alunos. 0 enfoque por tarefas permite tal flexibilidade. Além disso, o material proposto pode ser utilizado em cursos de diferentes durações, como oficinas, cursos intensivos e cursos regulares, dependendo do propósito a que se destina. Assim, esperamos que nosso material possa servir como base e motivação para o desenho de outras propostas didáticas voltadas à tradução de HQs, arte carente de atenção acadêmica na área dos Estudos da Tradução.

\section{Referências}

ACCÁCIO, M. A. Literatura infantil em tradução funcionalista com base no exemplo de Ein Feuerwerk für den Fuchs. 2010. 195 p. Dissertação (Mestrado em Estudos da Tradução). Universidade Federal de Santa Catarina, Florianópolis - SC. Disponível em:

www.pget.ufsc.br/curso/dissertacoes/Manuela_Acassia_Accacio_Dissertacao .pdf. Acesso em: 17 dez. 2015.

Celotti, N. The Translator of Comics as a Semiotic Investigator. In: Zanetin, F. (Ed.). Comics in Translation. Manchester: St. Jerome Publishing, 2008: 3349.

GALÁN MAÑAS, A. La enseñanza por competencias, por tareas y por objetivos de aprendizaje: el caso de la traducción jurídica portugués-español. Íkala, revista de lenguaje y cultura [online], 2007, v. 12, n. 18, pp. 27-57. Disponível em: www.redalyc.org/articulo.oa?id=255020488002. Acesso em: 10 fev. 2016.

González DaVIes, M. Multiple Voices in the Translation Classroom: Activities, tasks and projects. Amsterdam \& Philadelphia: John Benjamins, v. 54, 2004.

Groensteen, T. Comics and Narration. Jackson: University Press of Mississippi, 2013. Translated by Ann Miller. 
LIBERATTI, E. - Proposta didática para traduzir as histórias em quadrinhos

HATTNHER, Á. Um breve olhar teórico sobre histórias em quadrinhos. In: Das pinturas rupestres de Lascaux: uma viagem pelo universo dos quadrinhos / Arnaldo Pinheiro Mont'Alvão Júnior / Edgar Cézar Nolasco (Orgs.), pp. 35-47, João Pessoa: Marca de Fantasia, 2014. 218p.

HuRTADO AlBiR, A. La enseñanza de la traducción directa "general". Objetivos de aprendizaje y metodologia. In: HURTADo ALBIR, A. (Ed.). La enseñanza de la traducción. Castellón: Universitat Jaume I, 1996 (Col. Estudis sobre la traducció 3).

A aquisição da competência tradutória: aspectos teóricos e didáticos. In: Pagano, A.; Magalhães, C.; Alves, F. (Orgs.). Competência em Tradução: cognição e discurso. Belo Horizonte: Editora da UFMG, 2005: 19-57.

Enseñar a Traducir: Metodologías en la formación de traductores e intérpretes. Teoría y fichas prácticas. $2^{\mathrm{a}}$ reimpressão. Madri: Edelsa, 2007.

KaINDL, K. Comics in Translation. In: Gambier, I.; Doorslear, L. Van (Ed.). Handbook of Translation Studies. John Benjamins, v.1, 2010: 36-40. Disponível em: www.benjamins.com/\#catalog/books/hts.1/preview. Acesso em: 4 nov. 2015.

LiberatTI, E. Ara, Chico; Aw, Chuck: uma tradução funcionalista de quadrinhos do Chico Bento. 2012. 165 p. Dissertação (Mestrado em Estudos da Tradução). Universidade Federal de Santa Catarina. Florianópolis - SC. Disponível em: www.pget.ufsc.br/curso/dissertacoes/Elisangela_Liberatti_-_Dissertacao.pdf.

. Entrevista com Érico Assis, tradutor de histórias em quadrinhos. Revista In-Traduções, Florianópolis, v. 6, n. 10, pp. 287-293, 2014. Disponível em:www.incubadora.periodicos.ufsc.br/index.php/intraducoes/article/view/ $2801 / 3503$.

MCCLOUd, S. Desvendando os quadrinhos. São Paulo: Mbooks, 1995.

MILLER, A. Reading Bande Dessinée. Bristol: Intellect, 2007.

NoRD, C. Text Analysis in Translation: Theory, Methodology, and Didactic Application of a Model of Translation-Oriented Text Analysis. Translated by Christiane Nord and Penelope Sparrow. Amsterdam, Atlanta, Rodopi, 1991.

Ramos, P. E. Tiras, gênero e hipergênero: como os três conceitos se processam nas histórias em quadrinhos. In: SIGET - SIMPÓSIO INTERNACIONAL DE ESTUDOS DOS GÊNEROS TEXTUAIS, 6, 2011, Natal. Anais do VI Siget - Simpósio Internacional de Estudos dos Gêneros Textuais, 2011. Disponível em: www.cchla.ufrn.br/visiget/pgs/pt/anais/Artigos/Paulo\%20Ramos\%20\%28UNIFE SP\%29.pdf. Acesso em: 23 jan. 2016.

REIS, D. da S. Tradução e formação do mercado editorial dos quadrinhos no Brasil. Anais da III Jornada de Estudos sobre Romances Gráficos. Brasília, 
2012. Disponível em:

www.gelbc.com.br/pdf_jornada_2012/jornada_2012_06.pdf. Acesso em: 30 set. 2015.

RosA, G. M. A tradução quadrinhística: sinais de conflito entre imagem e texto. Revista TradTerm, v. 16, n. 1, pp. 411-434, 2010.

SILVA, A. C. da. Histórias e traduções em quadrinhos. Pôster apresentado no I Simpósio Nacional do Grupo MultiTrad, 2011. Disponível em: www.pt.scribd.com/doc/73277187/Traducao-de-Quadrinhos\#scribd. Acesso em: 10 jun. 2015.

Zanettin, F. Comics in translation. University of Perugia, Italy. St. Jerome Publishing, 2008. 